\title{
The Canadian oil sands: environmental, economic, social, health, and other impacts
}

\author{
C. A. Poveda \& M. G. Lipsett \\ Department of Mechanical Engineering, University of Alberta, Canada
}

\begin{abstract}
As world energy demands increase, so will the exploration and exploitation of alternative energy resources. The present level of energy generation cannot meet the needs of future generations if the pace of population growth and energy consumption continues at the current rate. While some unconventional energy sources are still in research and development phase, others have been effectively implemented. The impacts of different energy operations are still being debated, with respect to environmental, social, economic, and health effects. The definition of sustainable development adopted by United Nations (UN) uses the expression "...meets the needs of the present..." to indicate the required development by a current generation to maintain its standard of living while minimizing environmental, economic, social impacts. Large industrial developments will affect a range of stakeholders, and may entail cultural and political change. The level of impacts and their implications depends on many characteristics of the development, such as its size, production rate, duration of exploitation, processes used (including treatment of waste streams), and regulatory standards. While local communities, businesses and surrounding areas are first expected to be impacted, certain developments can attract global attention. Canadian oil sands developments are of interest to oil producers because of the size of the proven reserves; but the scale of development and the perceived enduring impacts are of concern to different stakeholders. This work presents a discussion and analysis of the economic, social, health, and other impacts of current operations in Canadian oil sands that are of concern to different stakeholders, including some uncertainties in levels and persistence of
\end{abstract}


impacts. An overview is provided of efforts undertaken by government and developers to minimize impacts; and comments are offered on possible future strategies.

Keywords: impacts, oil and gas, oil sands, sustainable development, energy consumption, unconventional oil.

\section{Introduction: oil and gas resources}

With continued growth in emerging economies around the world, the global oil demand has steadily grown over the past 20 years from 60 million barrels per day to 88 million [1]. Crude oil is not only one of the most traded commodities in the world, but also one of the most volatile; the commodity is influenced by a variety of factors that produce fluctuations in oil prices, thereby affecting supply and demand.

Production of oil and gas is classified as either conventional and unconventional: unconventional oil is extracted or produced using techniques other than the conventional oil well method. Since the sources of conventional oil are in decline, efforts are turning to unconventional reserves to meet the growing demands; however, unconventional oil production carries not only some extra monetary extra costs, but also a bigger environmental footprint. Moreover, conventional oil is easier extract, and creates fewer greenhouse gas emissions than unconventional oil production [1].

Conventional oil is either light or heavy, depending on its consistency (API gravity). Light oil can flow naturally to the surface or be extracted using pumpjacks (i.e., the oil well method). Extraction techniques for conventional oil have been used for decades; therefore, certain acceptable levels of efficiency in the extraction process have been accomplished, with incremental improvements in enhanced oil recovery. In contrast, development of efficient techniques for unconventional oil production. takes high levels of investment and considerable time; however, producers and developers recognize the necessity of optimizing extraction techniques, not only to increase production but also to reduce their environmental footprint.

The International Energy Agency (IEA) reports different sources of unconventional oil and gas: oil sands-based synthetic crudes and derivative products, oil shales, coal-based liquid supplies, biomass-based liquid supplies, and liquids arising from the chemical processing of natural gas [2]. Out of these unconventional oil sources, oil sands is at the top of the list, because the amount of proven reserves is very large, and the largest deposits are located in stable geo-political regions (e.g. Canada).

Canadian energy production has almost doubled since 1980 due to the rapid development of the proven oil sands reserves in the province of Alberta. As of 2010, Canada produces 1.22 million barrels per day of conventional oil, 1.5 million barrels per day of oil sands, and 14.7 billion cubic feet per day of natural gas, making Canada part of the global crude oil markets [2]. In fact, Canada's richness in oil and gas resources can be measured based on its global presence: it is the third largest producer of natural gas, the fifth largest energy producer, and 
the largest producer of crude oil with the biggest deposits of oil sands in the world [3].

The oil and gas industry in Canada is currently present in 12 of its 13 provinces and territories. In global oil reserves, Canada places third, following Venezuela and Saudi Arabia; however, the scenario is promising if feasible oil sands deposits in the province of Saskatchewan change from the non-proven to the proven reserves category.

Unconventional oil and gas extraction and production from any of the different sources raises a variety of concerns. Social, economic, health, and especially environmental impacts are expected; however, finding a balance among the three pillars of sustainability offers a feasible sustainable path. The primary affected pillar of sustainability noticed by stakeholders refers to environmental impacts; in unconventional oil and gas extraction and production, those impacts of major concerns include waste management, use of chemicals and energy, and air pollutions (e.g., GHG emissions). Major concerns arise due to the large amounts of mildly hazardous tailings and waste in the mining process during oil extraction and production. In addition to the concerns in light oil production, heavy oil requires the use of heat to pump the product out of the ground. Exploration of oil shale raises questions regarding net unit energy production efficiency and carbon dioxide emissions, in addition to oxides and pollutants and the use of chemicals mixing with underground water. Similarly, oil obtained from coal or natural gas produces large amounts of carbon dioxide.

Environmental impacts are not the only concerns related to unconventional oil and gas extraction and production; however, the general first impression of government, developers, local communities, and stakeholders regarding sustainable development refers to that specific pillar of sustainability (i.e., environmental). Social, economic, and health impacts involving the development of unconventional oil (e.g., oil sands) can be equally, if not more, relevant than those affecting the environment, as they are interconnected.

\section{The Canadian oil sands}

Put simply, oil sands are an unconsolidated mixture of sand, clay and/or other minerals, water, and bitumen; therefore, the extracted product must be treated before it can be used by refineries to produce usable fuels. Even though oil sands deposits can be found around the world, including Russia, Venezuela, the United States, and Colombia, Canada possesses not only the largest deposit in the world, but also the most developed, as advanced technology is used in the production process.

While Alberta's oil sands proven reserves are currently stated to be 178 billion barrels, the estimated total volume of bitumen in place is 1.6 trillion barrels [4]. The 178 billion of barrels can be recovered with current technology, and would be sufficient to meet the Canadian crude oil demand for approximately 250 years. The current developed area of the Canadian oil sands concentrates in three main areas (i.e., Peace River, Athabasca, and Cold Lake) located in the Province of Alberta; however, the development will eventually be 
extended to the Province of Saskatchewan. Surpassing Canada's conventional oil production, the daily production for Alberta's oil sands is approaching 1.7 million barrels [5]. And because a combination of unique factors - large untapped reserves, a stable political environment, and openness to investment in an environment of high oil prices [6] - Canada is expected to be the fourth largest oil producer by 2035.

The rapid development of the oil sands, which appears to be exponential, has raised major concerns for different sectors of society. Although Albertans recognize the economic benefits of the oil sands development, environmental, social, and health impacts that may be present in each phase of the life cycle are not to be ignored by those directly affected. These projects have grabbed not only national but also international attention.

The oil sands resource life cycle, as shown in Figure 1, starts with the assessment of prospects and ends with a reclamation process, which consists of leaving the exploration and production areas as equally productive (or equivalent environmental capability) as they were before their use. Independent of the extraction method utilized - surface mining or in-situ - companies proposing a development go through similar project approval processes, which generally include public consultation and a variety of required studies. The major impacts are encountered in the processes of recovery, upgrading, and refining: Canada's oil sands projects (extraction, upgrading, and distribution to downstream refineries) require multi-billion-dollar infrastructure, for which construction, operation, and maintenance affects primarily uninhabited land as well as local and Aboriginal communities.

\section{Sustainability: The triple bottom line}

Before 1987, when the Brundtland Commission (formally known as the World Commission on Environment and Development [WCED]) defined sustainable development, the movement did not enjoy major support, and its origins can be debatable. Since then, the development of sustainability assessment tools has faced unprecedented growth, and sustainable strategies have grabbed the attention of public and private organizations and stakeholders in general.

In Canada, the concept of sustainable development has been integrated into federal government policies, programs, and legislation; however, provincial and territorial governments are key partners in the development of projects in a sustainable manner $[7,8]$.

Canada's oil sands are not only an unconventional oil and gas resource, but also a non-renewable resource for which exploration, extraction, and production challenge the different stakeholders' ability to meet the needs of the present without compromising for the needs of future generations. As social, economic, environmental, and health impacts occur during the development of the oil sands, a sustainable path consists of finding the balance to different stakeholder needs, which are influenced by the different positive and negative impacts encountered in any of the three pillars of sustainable development (i.e., social, economic, and environmental). 
Interdependency and balance between impacts and gains (benefits) is meant to be understood by observing the graphic representation of sustainable development, which is usually shown using 3 mutually intersected circles. Gibson et al. [9] describe the fundamentals of sustainability as a mindset where "economic imperatives rule, social arrangements are judged by how well they serve the economy, and the biosphere (environment) is treated mostly as a source of resources.” But economic factors are major drivers in the decision-making process [10].

The balance between impacts and gains is influenced by perception and subjectivity. While environmental impacts are usually observed as negative, economic impacts place on the other side of the spectrum. Subjectivity refers to factors like priorities and emphases, which level of confidence stakeholders and experts have regarding the feasibility and sufficiency of certain approaches, and what makes the list of priorities and considerations to meet the needs of policy and project activities [9]. Oil producers are advertising in public media to emphasize that economic benefits are not regional, but rather national.

Economic impacts are mostly interpreted as positive. Negative environmental impacts are obvious, but progress is being made on reducing energy intensity and disturbed land footprint (although with additional projects the overall rate increases). Social impacts, for the most part, are uncertain and immeasurable due to subjectivity and qualitative factors. Health impacts unpredictable, as some effects may appear long after the exposure to contaminants, and demonstrating the illness and source linkage needs credible and reliable evidence resulting from scientific intervention.

\subsection{Environmental impacts}

The rapid development of the oil sands has increased the pressure on Alberta's natural environment. The total area of Alberta's oil sands covers 140,200 km². To date, about $715 \mathrm{~km}^{2}$ of land have been disturbed by surface mining activities, and up to 1.25 percent of Alberta's boreal forest could potentially be disturbed, although not permanently [11].

The World Resources Institute (WRI) [12] reports well-documented environmental impacts of mining: presently [mining] is the primary method of oil sands extraction with $53 \%$ of the total production in 2010 and the other $47 \%$ using in-situ methods; however, only $20 \%$ of the oil sands is recoverable through mining, while approximately $80 \%$ is recoverable by in-situ processes [11]. While the WRI reported impacts make reference to mining in general, Alberta's oil sands are not excluded from facing similar challenges: waste management issues (sedimentation, acid drainage, metal deposition), impacts on biodiversity and habitat, indirect impacts, and poverty alleviation and wealth distribution. Furthermore, environmental impacts involving the oil sands development can be divided into impacts on land, air, and water resources.

As part of the land management and reclamation program and Alberta's legislation, disturbed lands must be productive again; therefore, companies must remediate and reclaim such areas meeting Alberta Environment's strict standards 


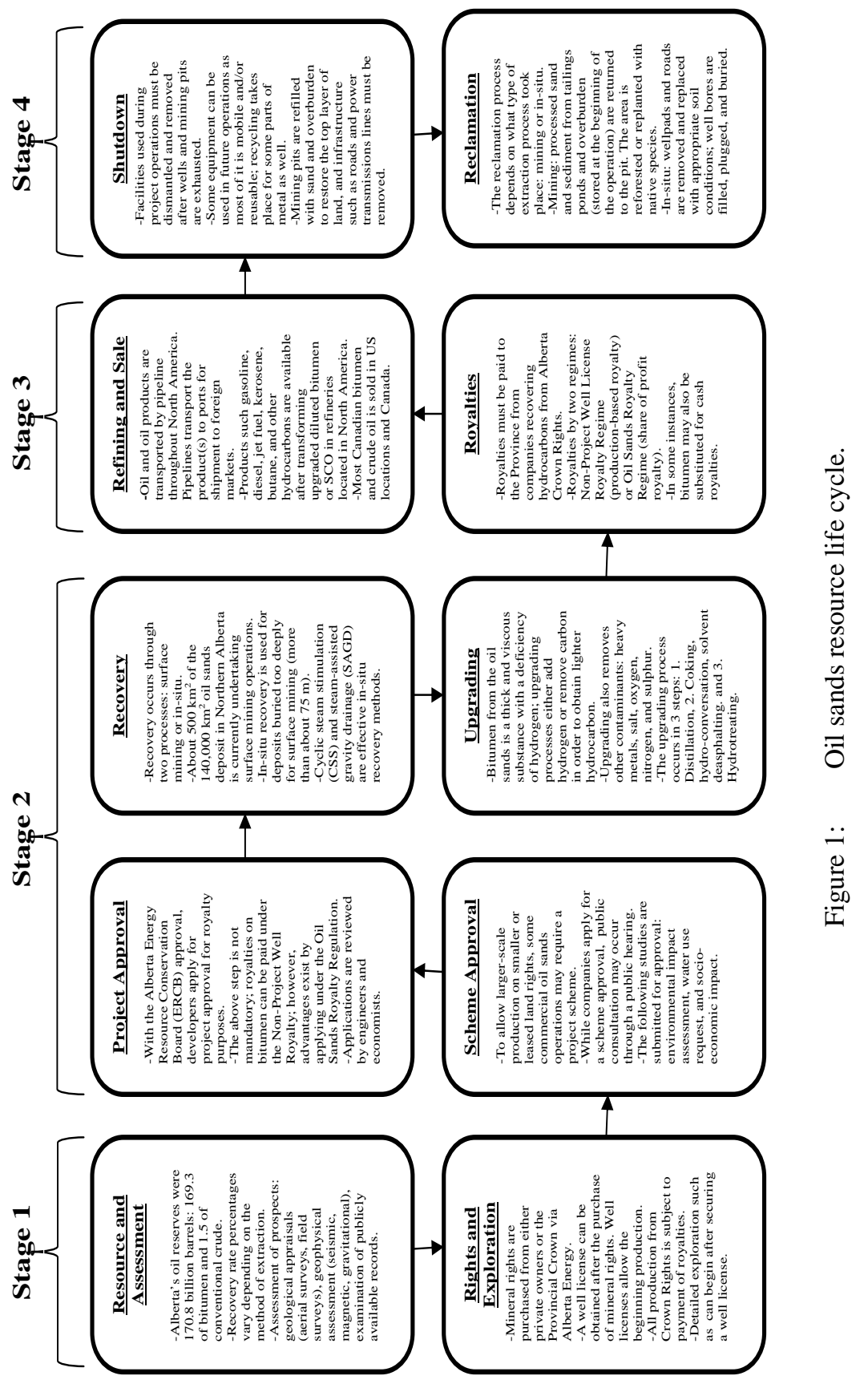


guaranteeing the land can support activities similar to its previous use. Currently, only $67 \mathrm{~km}^{2}$ of disturbed land have been reclaimed but not certified, which indicates less than 10 percent of the total disturbed area [13]. Moreover, Gosseling et al. [10] report on reclamation and adequacy of financial security, underlining that reclamation is not keeping with the pace of development, and "current practices for obtaining financial security for reclamation liability leave Albertans vulnerable for major financial risks” [10].

Impacts on air as a resource are one of the major worries for government, developers, local communities, and other stakeholders. More than 1,400 known pollutants are emitted by oil sands operations, but only a few are monitored: sulphur oxides $\left(\mathrm{SO}_{\mathrm{x}}\right)$, nitrogen oxides $\left(\mathrm{NO}_{\mathrm{x}}\right)$, hydrocarbons, and fine particulate matter $\left(\mathrm{PM}_{2.5}\right)$ [10]. Even though the Canadian oil sands projects have reduced their carbon dioxide emissions intensity by up to 33 percent since 1990, their contribution to the Canadian greenhouse gas emissions (GHGs) account for 6.5 percent of the nation's total, and less than 0.1 percent to the world's total GHG emissions. Additionally, the GHG emissions per barrel have been reduced between 1990 and 2009 by an average of 29\%; however, emissions of $\left(\mathrm{SO}_{\mathrm{x}}\right)$ and other sulphur compounds $\left(\mathrm{NO}_{\mathrm{x}}\right)$, as well as total hydrocarbons, have been rising for the past decade due to the growing increments in production [10]. Alberta Environment measures the cleanliness of outdoor air, also known as ambient air, through the Air Quality Index (AQI), which includes the measurement of concentration of five major air pollutants: carbon monoxide, nitrogen dioxide, ozone, sulphur dioxide, and fine particulate matter. In reference to air quality, the Royal Society of Canada (RSC) concluded that there has been minimal impact from the oil sands, except for noxious odour emissions, over the past two years [10]. However, odours can only be assessed subjectively, using trained observers.

In 2009, 90 facilities in Alberta reported that their combined GHG emissions equalled 113.1 megatonnes in carbon dioxide equivalent (Mt of CO2e). About 41.9 Mt of CO2e are emissions from oil sands facilities: 26.9 Mt of CO2e are from the oil sands mining and upgrading, and $15 \mathrm{Mt}$ of CO2e are from in-situ projects' facilities. In 2011, oil sands production emitted an estimated 80 million tons of CO2 [14]. The production and upgrading of the oil sands are more energy-intensive than the production of conventional oil; as a result, higher GHG emissions are expected. However, if considering the complete life cycle, which includes the refinement, transportation, and consumption of oil, 80 percent of the total emissions occur at the end of the cycle (consumption) from burning fuel. Nevertheless, the new levels of bitumen production create challenges for Canada to meet international commitments for overall GHG emissions reduction, which the current technology does not resolve [10].

Water consumption, contaminants emissions, and groundwater quality and quantity are three of the major concerns in reference to water resources. Water consumption in the oil sands development projects varies based on whether the extraction method utilized is in-situ or surface mining. In mining operations, 2.5 to 4 barrels of water is used for every barrel of bitumen produced; however, up to 90 percent of the water utilized is recycled, and as a result, only 0.5 barrels of 
water is needed to make up for the deficit [11]. As for surface mining operations, 7.5 to 10 barrels of water is used per barrel of bitumen, but the recycle rate is currently up to 70 percent, translating to 3 to 4.5 barrels of water to make up for the deficit to maintain production [11].

Almost all of this water is captured in the pores of tailings deposits, produced in the process of separating bitumen from the oil sands. Inventories of hydrocarbon-contaminated water are impounded in earth dams or in mined-out pits. Untreated water is not to be released to water bodies off the mine site. Oil sands tailings comprise water, sand, clay, residual bitumen, and chemicals, which includes small amounts of polycyclic aromatic hydrocarbons (PAHs), naphthenic acids, heavy metals, and mineral ions. The functions of the ponds are to provide a disposal area for coarse and fine tailings, to allow water to separate from solid waste materials, to store water from recycling, and to hold contaminants [13]. Even though new technologies have emerged for improving tailings management, these have not stopped the growing inventory of tailings ponds.

An additional factor in water management refers to groundwater quantity and quality. Not only concerns about the Regional Aquatics Monitoring Program (RAMP) have been raised, but also the regional cumulative impact on groundwater quantity and quality has not been assessed [10].

\subsection{Social impacts}

If sustainability is still in its infancy, then the social dimension is the youngest of the three pillars; however, it is not less relevant than the other two (economic and environmental). Based on the equality factor, the three dimensions are interchangeably relevant, and a sustainable path translates to a balance between the three dimensions. The social dimension of sustainable development is subjective, qualitative, difficult to assess, and involves stakeholders' diverse views on the issues; but it is recognized that social impacts occur at different social scales involving individuals, families, businesses, community groups, communities as a whole, ethnic groups, cultures, and broader society [8]. Individuals will identify with some or all of these divisions.

Social impacts are, as expected, linked to other types of impacts such as health. In the Athabasca region, the health indicators are consistent with the "boom town" effect. Small towns suddenly face rapid growth, which affects communities' health and social infrastructure. Gosselin et al. [10] indicate that the Government of Alberta has recognized some of the shortfalls due to the rapid population growth caused by the accelerated pace of the oil sands development; however, there is no evidence of addressing the serious population health issues. In fact, it has been recognized that better understanding is needed about the social impacts of development on some Alberta regions (e.g., Forth McKay, Fort McMurray), including demographic information regarding population changes, migration, and the impact of migration patterns (such as labour force statistics and income statistics) [15].

Even though the lack of statistical data makes it difficult to assess the different impacts, concerns have been raised by Aboriginal and local 
communities, including the influx of non-Aboriginal people onto traditional lands, the loss of traditional resources due to development, the level of migration of people to local communities, the outward migration of First Nation and Métis communities due to lack of housing, and the loss of traditional culture. Additionally, Shipley [15] highlights some effects of the oil sands development on education: funding conditions, infrastructure costs, staff recruitment and retention, and the effectiveness of adult education programs and their barriers.

Additional concerns have been raised due to the use of industrial camps. Because of the size of the oil sands development and the large number of personnel required to build, operate, and maintain the projects, developers often use industrial camps to allocate personnel, rather than relying on housing in the community (which has a very low vacancy rate). This type of allocation generates a series of additional concerns, including but not limited to the increased potential of forest fires, recreational pressure on the environment, safety (primarily the increased number of vehicles on local roads), and the potential destruction of sacred sites [15].

Social impacts are expected to occur as the development of the oil sands projects goes on; however, in order to mitigate and/or eliminate the impacts, the first step towards a sustainable development consists of assessing the impact, followed by monitoring the programs. The main challenge encountered in achieving the assessment and monitoring the social impacts revolves around the fact that scientists and industry seem to be facing a major obstacle regarding two main questions: what should be measured (e.g., indicators), and how should they be measured (e.g., metrics). Government, developers, local communities, and other oil sands stakeholders are not exempt from stumbling upon similar issues.

\subsection{Economic impacts}

As one of the largest development projects in Canada's history, the cumulative investment in oil sands in the past decade alone has surpassed \$100 billion [6]. However, any discussion of the future and current economic impacts of Alberta's oil sands development is based on a series of assumptions and constraints, including (1) that the current announced project will proceed, (2) the size of the initial, remaining, and new established reserves, and (3) the current project will keep and/or increase production. The economic impacts (benefits) of Alberta's oil sands may differ from study to study based on the assumptions, constraints, and methodology used; however, findings always point toward a series of positive economic impacts instead of negative, as presented in some statistics ahead. Most studies measure economic impacts (therefore, the terms "positive" or "benefits" are used) in terms of changes in three major indicators: gross domestic product (GDP), employment and labour income, and government revenue [5 16 17]. Naturally, any major development of a resource with large reserves (e.g., unconventional oil) of national and/or international interest has inherently positive impacts on major economic indicators (e.g., GDP, employment, revenue); however, "real” (negative) impacts on the average citizen may be overlooked in the decision-making process, with the aim of giving the "green light” to development projects. 
The analysis of the economic impacts of the oil sands must not only take into consideration current operations, but also those projects that have grabbed the attention of government, stakeholders, and the public in general, related to transport of hydrocarbon products from oil sands projects: TransCanada's Keystone XL Pipeline; Enbridge's Northern Gateway Pipeline from Bruderheim, Alberta to the port of Kitimat, British Columbia; and Kinder Morgan's Trans Mountain Pipeline system's Northern Leg expansion to Kitimat, British Columbia.

Over the 2010-2035 period for different scenarios, the estimated investment, reinvestment, and revenues from the operation of the oil sands projects range from $\$ 2,197$ to $\$ 4,783$ billion [16]. The $\$ 4,783$ B estimate is reached with the assumption that announced oil sands projects will proceed and pipelines will be built to get the product out. While all provinces in Canada are affected by the development of the oil sands, Alberta carries the highest positive economic impact of all, followed by Ontario, British Columbia, Quebec, and Saskatchewan, respectively [6].

Honarvar et al. [5, 16] offer an analysis of the economic impacts of the oil sands development under these different scenarios over the 25-year period:

- The total Canadian GPD impact as a result of the investment shocks is estimated to range from $\$ 2,283$ to $\$ 4,925$ billion.

- Canadian employee compensation can range from $\$ 650$ billion to $\$ 1,417$ billion.

- Employment creation, including direct, indirect, and induced, is expected to grow from 390,000 up to 1,600,000 jobs in 2035 if the best scenario presents.

- Alberta royalties may grow from $\$ 3.56$ billion to $\$ 65.2$ billion.

Additionally, the US market is expected to be economically impacted by the oil sands development:

- US GDP impacts as a result of the investment shocks is estimated to range from CAD $\$ 210$ to CAD $\$ 775$ billion.

- US employee compensation can range from $\$ 100$ billion to $\$ 68$ billion.

- US employment, including direct, indirect, and induced, is expected to grow from 80,000 up to 600,000 jobs in the best of the scenarios.

The lower range value in each case represents the economic impacts of existing operations and those that are still under construction. The top range value assumes that all the announced oil sands projects will proceed, and pipelines will be constructed with adequate capacity to move the product. Existing pipeline export capacity is at 3.5 million barrels per day (MMBPD) of crude oil, and in the best scenario, the capacity will increase up to 7 million barrels per day (MMBPD).

Although still positive, the Conference Board of Canada presents a slightly different employment forecast through a detailed supply chain analysis. \$364 billion in price-adjusted investment is expected for the next 25 years, which will support 3.2 million person-years of employment in Canada (880,000 personyears of direct employment) [6].

Not everything regarding economic impacts of the oil sands is positive, and even though economic impacts mostly sound positive due to high levels of cash 
flow as a consequence of the rapid development of the project, there is another side of the coin. Shipley [15] discusses negative impacts, which include the cost of living as impacted by development. This translates into suitable accommodation for new residences, affordable and comfortable homes for regional residents, and the ability to attract and retain employees. Additionally, concerns regarding housing include increased costs of building material, increased costs and scarcity of tradespersons, high building and maintenance costs, and high costs of rental property, which affect those with low-paying jobs.

\subsection{Health and other impacts}

Similar to other impacts, the oil sands development projects' impacts on health require rigorous monitoring. Though some effects on health are measurable in the short term, other impacts affecting local communities may not appear until after several years have passed.

For those health indicators that are monitored in the Regional Municipality of Wood Buffalo (RMWB), the majority of those indicators show poorer levels than other Alberta regions and the provincial average. Based on current levels of monitoring, there is not credible evidence of environmental contaminant exposures causing elevated human cancer rates; however, rigorous monitoring is needed to find the causes and to address the concerns of First Nations and other communities [10]. Additionally, public health cannot be limited to exposure to environmental contaminants, since there are other health indicators to assess major negative effects on local communities. Health impacts are tightly linked to other impacts (e.g., environmental and social); therefore, finding the link between cause and effect becomes a priority in areas of rapid development (e.g., the Athabasca region [Alberta]) to effectively, rapidly, and efficiently mitigate and/or eliminate the risks.

In addition to economic, social, environmental, and health impacts, Alberta's oil sands development carries other potential impacts due to disruption to ecosystems and local communities. The oil sands projects require access to land, other natural resources such as water, and subsequent land development to accommodate the needs for the execution, operation, and maintenance of the projects, not only during construction but also during operations and decommissioning.

In addition to conflicts between different land users that may arise, Aboriginal and local communities may oppose the development of the projects. Government provides funding to address community needs and develops new regulations to address social concerns. Some stakeholders criticize that the regulations imposed by regulatory bodies are not stringent enough. Developing companies have implemented programs for stakeholder engagement to improve their relationships and obtain the so-called "social license." Furthermore, local communities in the role of "active" or "inactive" stakeholders are ready to act as issues concerning them arise.

A common worry amongst Albertans involves the equality factor. The oil sands resource results in not only provincial but also national economic growth. However, the benefits of mining are not always equally ("fairly") shared [12]; 
the same feeling of "unfairness" is shared by some Albertans who believe that the resource belongs to the province, and it is argued that Albertans do not get their "fair" share from other industries/resources (e.g., fishing) existing in other provinces. This issue of fairness is felt in other regions, and it can affect interjurisdictional negotiations, such as conditions for British Columbia approval of the Northern Gateway pipeline project.

\section{Conclusions}

Canada's oil sands are in an advantageous and unique position as the biggest deposit of unconventional oil and gas in the world. Conventional oil sources face not only the threat of scarcity, but also unequal geographic distribution of the remaining oil; therefore, unconventional oil sources have grabbed national and international attention. For most, the volume of the deposits has taken the back seat, since the current technology will enable 178 billion of barrels to be recovered and meet the Canadian demand for about the next 250 years. The attention has now shifted to improving technology involving the extraction of the remaining resource, and identifying and mitigating the increasing impacts (social, economic, and environmental) inherent in the exploration, extraction, and production processes of the resource.

Indisputable, varied impacts are expected with the development of large scale projects; the focus of government, developers, local communities, and other stakeholders is not only to mitigate and/or eliminate impacts, but also to find a balanced approach for social, economic, and environmental needs. The rapid development of the Canadian oil sands may have taken government and developers by surprise; such development is under pressure by oil importers who see Canada as an ally that brings a feasible energy resource alternative with considerably-sized deposits that are in the middle of a stable geo-political scenario.

Efforts made by government and developers towards mitigating and/or eliminating impacts are falling short from the standpoint of local communities, environmentalists, national and international watchdogs, and other stakeholders. Not only is the on-going assessment, monitoring, and reporting of performance required, but stakeholder engagement in decision-making and informing/educating the public is also essential to facilitate and benefit the process.

\section{References}

[1] Canadian Association of Petroleum Producers (2012). Oil. Retrieve from http://www.capp.ca/canadaIndustry/oil/Pages/default.aspx. December 2012.

[2] International Energy Agency (2012). Oil Market Report. Retrieve from http://www.capp.ca/energySupply/canadaPetroleumResources/Pages/defaul t.aspx. December 2012. 
[3] Canadian Association of Petroleum Producers (2012). Canada's Petroleum Resources. Retrieve from http://www.capp.ca/energySupply/canada PetroleumResources/Pages/default.aspx. December 2012.

[4] Alberta Energy and Utilities Board (2004). Alberta's Reserves 2003 and Supply/Demand Outlook 2004-2013, June 2004 Revised Version. Retrieve from http://www.eub.gov.ab.ca/bbs/products/STs/st98-2004 December $\underline{2012}$.

[5] Honarvar, A., Rozhon, J., Millington, D., Walden, T., and Murillo, C.A. (2011). Economic Impacts of New Oil Sands Projects in Alberta (20102035). Canadian Energy Research Institute. Study No. 124.

[6] The Conference Board of Canada (2012). Fuel for Thought: The Economic Benefits of Oil Sands Investment for Canada's Region. The Conference Board of Canada: Report October 2012.

[7] National Resources Canada.(2011a). Whitehorse Mining Initiative. Retrieve from http://www.nrcan.gc.ca/minerals-metals/policy/government-canada /3882. December 2012.

[8] United Nations. (undated). Canada National Reporting to CSD-18/19 Thematic Profile on Mining. Retrieve from http://www.un.org/esa/dsd /dsd_aofw_ni/ni_pdfs/NationalReports/canada/Mining.pdf December 2012.

[9] Gibson, R. B., Hassan, S., Holtz, S., Tansey, J., and Whitelaw, G. (2010). Sustainability Assessment: Criteria and Processes. London, UK: Earthscan.

[10] Gosselin, P., Hrudey. S. E., Naeth, M. A., Plourde, A., Therrien, R., Van Der Kraak, G., and Xu, Z. (2010). The Royal Society of Canada Expert Panel: Environmental and Health Impact of Canada's Oil Sands Industry. The Royal Society of Canada.

[11] Alberta Energy (2012). Facts and Statistics. Retrieve from http://www.energy.gov.ab.ca/OilSands/791.asp. December 2012.

[12] WRI (undated). Appendix 2: Environmental and Social Impacts of Mining. Retrieve from http://pdf.wri.org/mining background_literature_review.pdf . December 2012.

[13] Environment Canada (2009). Environmental Management of Alberta's Oil Sands: Resourceful. Responsible. Government of Alberta.

[14] Salameh, M. G. (2012). The potential of Unconventional Oil Resources: Between Expediency \& Reality. International Association for Energy Economic. Fourth Quarter 2012 Report.

[15] Shipley, K. (2005). Socio-Economic Impact Assessment Review: Albian Sands Energy Inc. Muskeg River Mine Expansion. Report prepared for The Fort McKay Industry Relations Corporation: August 2005.

[16] Honarvar, A., Rozhon, J., Millington, D., Walden, T., and Murillo, C.A. (2011). Economic Impacts of Staged Development of Oil Sands Projects in Alberta (2010-2035). Canadian Energy Research Institute. Study No. 125 Section I.

[17] Timilsina, G. R., LeBlanc, N., and Walden, T. (2005). Economic Impacts of Alberta's Oil Sands. Canadian Energy Research Institute. Volume I. Study No. 110. 